\title{
Building Alliances from Ambivalence: Evaluation of Abortion Values Clarification Workshops with Stakeholders in South Africa
}

\author{
Ellen MH Mitchell', Karen Trueman², Mosotho Gabrieß and Lindsey B Bickers Bock ${ }^{4}$
}

\begin{abstract}
A retrospective evaluation of attitudinal, behavioural and knowledge change among diverse stakeholder groups was conducted in Limpopo Province of South Africa to assess the effectiveness of a series of values clarification (VC) interventions. Telephone and face-to-face interview (193) results revealed that over two-thirds $(70.2 \%)$ reported behavioural changes and $93.2 \%$ reported increased compassion for women who seek and providers who render termination of pregnancy. Behaviours supportive of the law were more likely among those initially undecided about their opinion of termination of pregnancy $(p<0.05)$ than among those initially opposed or supportive to it. When combined with supportive follow-up, three-day VC workshops may be effective at increasing CTOPA knowledge, changing attitudes and spurring advocacy behaviour to support reproductive choice. Research studies with pre-post and case-control designs are needed to confirm these preliminary results.
\end{abstract}

(Afr J Reprod Health 2005; 9[3]:89-99)

\section{RÉSUMÉ}

Le développement des alliances à partir des ambivalences; Evaluation des ateliers de clarification de valeurs de l'avortement avec les intéressés en Afrique du Sud Une évaluation retrospectine des modifications sur le plan de l'attitude, du comportement et de la connaissance parmi les divers groupes d'intéressés a été menée dans la Province Limpopo d'Afrique du Sud afin d'évaluer l'efficacité d'une série d'interventions de la clarification des valeurs (CV). Les résultats des interviews par téléphone et face à face (193) ont montré que les deux tiers $(70,2 \%)$ ont signalé des modifications au niveau du comportement et que $93,2 \%$ ont signalé une hausse dans la compassion pour les femmes qui recherchent l'interruption de grossesse et les fournisseurs qui l'assurent. Les comportements qui soutenaient la loi étaient plus possibles chez celles qui, au départ, n'étaient pas sûres de leurs opinions à l'égard de l'interruption de grossesse $(\mathrm{p}<0,05)$ que chez celles qui dès le départ y étaient opposées ou qui la soutenaient. Si l'on combine les ateliers de trois jours de CV avec des suivis de soutien, les ateliers peuvent être efficaces pour augmenter la connaissance de CTOPA, la modification d'attitudes et peuvent motiver le plaidoyer de comportement en faveur du choix de reproduction. Il faut des recherches de modèle pre-poste et de cas témoin pour confirmer ces résultats préliminaries. (Rev Afr Santé Reprod 2005; 9[3]:89-99)

KEY WORDs: Abortion, behaviour, attitude, partnership, advocacy, Limpopo

'Research Associate, Ipas. ${ }^{2}$ Senior Training and Services Advisor, Ipas, South Africa. ${ }^{3}$ Country Director, Ipas, South Africa. ${ }^{4}$ Health Education Specialist, Duke University.

Correspondence: Ellen MH Mitchell PhD, Research Associate, Ipas, 300 Market Street, Suite 300, Chapel Hill NC 27516, USA. Tel: (919)967-5640; E-mail:mitchelle@ipas.org

\section{Introduction}


90 African Journal of Reproductive Health

Although legal barriers to safe abortion in South Africa were lifted in 1996 after years of struggle, pervasive misunderstanding of the abortion law persists. ${ }^{1}$ Access to services remains limited in rural and lower-resource settings. ${ }^{2}$ This project evaluates the effectiveness of an intervention called values clarification (VC) workshops, which was designed to foster support for reproductive rights among participants from diverse backgrounds. Values clarification is designed for stakeholders who may influence availability of and access to reproductive health-care. The expected outcomes may include decreased opposition to termination of pregnancy (TOP) services, community support of women seeking services, advocacy for TOP services, or provision of direct services.

In 2002, the Limpopo Department of Health and Welfare (DoH) invited Ipas, an international non-governmental organisation with expertise in abortion policy, clinical training and research, to assist with the design, facilitation and sponsorship of VC workshops. The workshops had the dual purpose of educating diverse constituencies and involving them in the fulfilment of the Choice in Termination of Pregnancy Act (CTOPA). In 2004, an evaluation was designed by a team of researchers and practitioners to measure the capacity of the workshops to improve CTOPA knowledge, attitudes and behaviours.

VC workshops are designed to shift attitudes and behaviours toward a less judgmental and more constructive approach to CTOPA, as well as to serve as a channel for soliciting the support of a given community for inauguration of new TOP services - a major priority of the Limpopo DoH. ${ }^{3}$ Limpopo is the province of South Africa where access to TOP services is possibly the most inadequate. A survey of TOP services conducted during 2000 rated Limpopo as the province with the lowest per capita rate of safe TOP procedures as well as the lowest contraceptive prevalence. ${ }^{4}$ This rural province was ranked next to last in the number of functioning TOP facilities. Resistance to TOP service implementation - manifest in the forms of obstructive management, lack of staff allocated to provide the service and lack of adherence to national norms and legislation - has resulted in many designated facilities being unable to offer life-saving TOP services. ${ }^{5}$ Judgmental, and at times hostile, working conditions for TOP providers in the public sector have hindered training and staff retention efforts. ${ }^{6,7}$ Where TOP services are available, they frequently rely on a single willing midwife or exist precariously, subject to the will of one facility manager, cleric or local politician. ${ }^{8}$

VC workshops, which were used successfully during the transformation process of health systems in South Africa in the late 1990s, were regarded by the Limpopo $\mathrm{DoH}$ as a credible vehicle for addressing the situation. ${ }^{9}$ In response to the promulgation of the CTOPA in 1996, the Planned Parenthood Association of South Africa (PPASA) conducted a pilot evaluation of seven one-day VC workshops in the Western Cape and found them to be an effective way of changing attitudes toward TOP. ${ }^{10}$ However, evaluations have not looked at more intensive three-day values clarification interventions or assessed participant behavioural outcomes. ${ }^{11}$

\section{Values Clarification Workshop Intervention}

The intent of the Limpopo DoH and Ipas VC workshop collaboration was to reach six priority stakeholder groups. The six main groups were traditional leaders, traditional healers, midwives, members of faith-based organisations, municipal councillors and health facility managers. These were selected because of their important gatekeeping and TOP service delivery roles in Limpopo. In order to reach the target groups in the six districts of this rural province, 22 workshops were held, seven $(31.8 \%)$ of which included mixed groups of participants. Despite the mixing of stakeholders and variation in facilitation, core content areas remained relatively

African Journal of Reproductive Health Vol. 9 No.3 December 2005 
Building Alliances from Ambivalence: Evaluation of Abortion Values Clarification Workshops with Stakeholders in ...

the same in all workshops. ${ }^{12}$

The core content used in the VC workshops came from Health Workers for Choice: Working to Improve Quality of Abortion Services. ${ }^{13}$ The manual is an adaptation of the 1995 edition of Health Workers for Change: A Manual to Improve Quality of Care. ${ }^{14}$ As a descendant of Health Workers for Change, the Health Workers for Choice curriculum uses active equal participation as a mode of learning versus traditional didactic pedagogy and the hierarchical teacher-learner model. ${ }^{15,16}$

\section{Methods}

A retrospective multi-method design was used to assess the impact of the workshops at the individual, community and facility levels. Qualitative and quantitative assessments of personal transformation were collected from 193 workshop attendees. Post-intervention telephone and faceto-face interviews were conducted to measure knowledge, attitudinal and behavioural indicators of change. The formative study was designed to answer the following three main questions:

(1) Was there a self-reported positive shift in participants' attitudes toward the CTOP Act, providers and/or clients?

(2) Was there a positive change in participants' self-reported knowledge and behaviours regarding abortion, both micro (individual) and macro level (collective)?

(3) How might the intervention be improved?

A thorough initial assessment of participants' knowledge, attitude and advocacy behaviour regarding the CTOPA prior to the workshops was not conducted due to literacy, communication and organisational constraints. Therefore, all participant information on initial knowledge, belief and attitude was gathered retrospectively, with the attendant risk of error due to problems with recall and social desirability bias.

The assessment also included interview with workshop facilitators and review of workshop reports and action plans. The interview allowed facilitators to highlight strengths and weaknesses of the project and discuss any challenges they had in implementing the workshops. By reviewing workshop reports and action plans, the research team was able to establish that the workshops were faithfully and uniformly implemented using the intended participatory methodology and content. ${ }^{17}$ Five experienced data collectors were trained to conduct the interviews and perform facility visits. Ethical review of the project was conducted by the University of the North West in Mafikeng, North West Province.

\section{Sample Size}

Sufficient contact information (telephone number or physical address) for visitation or telephone survey was only available for $373(57.8 \%)$ of the 645 participants due to administrative errors. Although attempts were made to interview the universe of 373 eligible respondents, only 193 $(51.7 \%)$ of the participants could be interviewed due to changes in respondent status (job re-assignment, mortality, migration and retirement) or contact information (cell phone cancellation). The overt refusal rate for telephone interview was only $2.6 \%$, whereas the proportion refusing faceto-face interview was $4.5 \%$. In the final sample, over half of the interviews $(55.9 \%)$ were conducted by telephone, while $44.2 \%$ were conducted in person.

\section{Statistical Analyses}

Bivariate analyses were performed using SPSS version 11.5 to explore relationships between participant characteristics and self-reported changes in knowledge, attitude and behaviour. Pearson's chi-square test was used to discern significant differences between proportions, and the level of significance was set at 0.05 . Thematic content analysis of manually-coded, open-ended responses were performed by two trained analysts. 
92 African Journal of Reproductive Health

Sample Characteristics

As shown in Table 1, participants in the sub-sample of participants who responded to the call for interviews were predominantly female (74.1\%), and represented a broad range of often overlapping community and health constituencies across all six districts in the province. Midwives and nurses represented over a quarter of the sample $(26.9 \%)$, followed by traditional healers and leaders (19.2\%). Interviews were conducted using four of the eight major languages spoken in Limpopo.

Table 1 Sample Characteristics $(\mathbf{n}=193)$

\section{Results}

\section{Initial Participant Knowledge}

Participants were asked retrospectively if they were able to adequately explain the CTOP Act to others prior to their attendance at the workshop. Over half (53.6\%) of participants asserted that, prior to the workshops, they were already capable of explaining the CTOP Act to others.

\begin{tabular}{|c|c|c|}
\hline & $\mathrm{n}$ & $\%$ \\
\hline \multicolumn{3}{|l|}{ Gender } \\
\hline Female & 143 & 74.1 \\
\hline Male & 46 & 23.8 \\
\hline Missing data & 4 & 2.1 \\
\hline \multicolumn{3}{|l|}{ Health workers } \\
\hline Nurses and midwives & 53 & 26.9 \\
\hline Health facility management & 17 & 8.8 \\
\hline Social workers & 14 & 7.3 \\
\hline \multicolumn{3}{|l|}{ Community participants } \\
\hline Traditional healers and leaders & 37 & 19.2 \\
\hline Municipal politicians & 35 & 18.6 \\
\hline Representatives of faith-based organisations & 20 & 10.4 \\
\hline Community liaison officers & 17 & 8.8 \\
\hline \multicolumn{3}{|l|}{ District } \\
\hline Capricorn & 61 & 31.6 \\
\hline Vhembe & 42 & 21.8 \\
\hline Mopani & 38 & 19.7 \\
\hline Waterberg & 18 & 9.3 \\
\hline Bohlabela & 15 & 7.8 \\
\hline Sekhukune & 14 & 7.3 \\
\hline Missing data & 5 & 2.5 \\
\hline \multicolumn{3}{|l|}{ Language of interview } \\
\hline English & 134 & 69.5 \\
\hline Tsonga/Shangaan & 30 & 15.5 \\
\hline Sotho/Sepedi & 28 & 14.5 \\
\hline Venda & 1 & 0.5 \\
\hline
\end{tabular}




\section{Initial Participant Attitudes}

A clear majority $(63.2 \%)$ reported feeling comfortable discussing termination of pregnancy with peers. However, over half $(58.0 \%)$ reported that they held firm established beliefs about abortion prior to attendance, hinting at a limited propensity for modification. When asked specifically about feelings toward termination of pregnancy, one-tenth $(10.4 \%)$ described their initial position as strongly opposed, $15.6 \%$ were generally opposed and $26.0 \%$ were undecided upon arrival. Among those predisposed to TOP, 26.5\% were generally supportive and $21.5 \%$ described themselves as strongly supportive.

\section{Initial Participant Behaviour}

When asked about their prior activist behaviour on reproductive health, $64.9 \%$ of attendees reported that they had already been working to overcome barriers to increasing access to safe termination of pregnancy in Limpopo. Some participants, specifically the midwives, were undergoing concurrent clinical training in abortion care.

\section{Post-Intervention CTOP Act Knowledge}

When asked about specific entitlements and protections of the national CTOP Act, participants demonstrated a fair degree of knowledge on most aspects. Most participants were aware of women's $(90.2 \%)$ and adolescents' $(81.3 \%)$ legal decision-making autonomy and the legal penalties for obstructing the law $(85.0 \%)$.

As Table 2 indicates, after the workshops, a considerable proportion of participants remained unclear on the broad range of conditions under which second trimester services are legal. Fewer than half of participants $(40.3 \%)$ realised that

\section{Table 2 Knowledge of Selected Aspects of the CTOP Act $(\mathrm{n}=193)$}

\section{Question}

Correct answers

$(\%)$

The CTOP Act requires husbands or boyfriends to give written consent before a

Up to how many weeks of pregnancy can a woman request TOP by a trained

The CTOP Act mandates financial penalties and up to 10 years imprisonment for

people who attempt to obstruct women's right to TOP services. [True]

The CTOP Act requires pregnant adolescents to obtain written parental consent

before they can undergo a TOP. [False]

Can a woman have a TOP in the second trimester if the pregnancy resulted from

rape or incest? [Yes]

Can a woman have a TOP in the second trimester if the pregnancy threatens the physical health of the woman? [Yes]

Can a woman have a TOP in the second trimester if the foetus has probable

developmental defects? [Yes]

Can a woman have a TOP in the second trimester if the pregnancy threatens the

mental health of the woman? [Yes]

Can a woman have a TOP in the second trimester if the pregnancy would

significantly affect the social and economic circumstances of the woman? [Yes]

African Journal of Reproductive Health Vol. 9 No.3 December 2005 
94 African Journal of Reproductive Health

TOP is legal up to 20 weeks when the pregnancy negatively affects the social and economic circumstances of the woman.

\section{Participant Attitudinal Shifts}

The vast majority of participants (97.4\%) affirmed that the VC workshops increased their personal awareness of their own feelings. Table 3 reveals increased self-reported "compassion" regardless of participants' original position on the TOP issue. Those initially undecided about TOP were slightly more likely to report that their personal beliefs about abortion were influenced by the workshop, but the difference did not reach statistical significance and the direction of the influence was not queried. The majority of participants reported increased empathy. However, those initially opposed to TOP were less likely to report that the workshop inspired empathy for providers and women who need TOP. Participants who were initially against TOP didn't necessarily change their personal views, but many did indicate a better understanding of the reasons TOP services need to be available. For example, a male municipal councillor from Capricorn, who noted that prior to the workshop "I wanted nothing to do with that [TOP]" said: "I am able to talk about and correct myths. I discuss with friends, also with my family relatives [sic]."

A midwife from Sekhukune noted that before the workshops she considered the Act to be against her beliefs, but during the workshop she "learned to be more lenient on people requesting counselling for TOP”. Open-ended responses suggested new appreciation of both the potential personal and broader societal benefits of having TOP services available. A municipal councillor from Vhembe observed:

\section{I had a religious belief that doing abortion was a sin. I now know that there are certain personal circumstances that warrant abortion. Safe TOP saves a lot of lives and reduces complications resulting from backstreet abortions. I also understand TOP to be saving government time and resources.}

Many participants' initial beliefs tended to reflect a lack of understanding of the contextual factors involved in a woman's decision to have an abortion and confusion regarding the safety of the procedure. In some cases, the workshop was only one of several stimuli that led to a change in perspective. A nurse from Bohlabela noted:

Table 3 Self-Reported Attitudinal Shifts attributed to the VC Workshop $(\mathrm{n}=188)$

\begin{tabular}{|c|c|c|c|c|}
\hline Did the VC workshop... & $\begin{array}{c}\text { Previously } \\
\text { positive toward } \\
\text { TOP }(\%) \\
(\mathrm{n}=92)\end{array}$ & $\begin{array}{c}\text { Previously } \\
\text { undecided } \\
\text { about TOP } \\
(\%) \\
(n=47)\end{array}$ & $\begin{array}{l}\text { Previously } \\
\text { opposed to } \\
\text { TOP (\%) } \\
(\mathrm{n}=49)\end{array}$ & $\begin{array}{c}\text { Total } \\
(\%) \\
(n=188)\end{array}$ \\
\hline $\begin{array}{c}\text {.. influence your thoughts or } \\
\text { personal beliefs about the } \\
\text { complex issues of abortion? }\end{array}$ & 76.1 & 81.6 & 72.0 & 76.2 \\
\hline $\begin{array}{l}\text {... inspire compassion for people } \\
\text { who provide TOP care? }\end{array}$ & 97.8 & 97.9 & $87.5+$ & 93.2 \\
\hline $\begin{array}{l}\text {... inspire compassion for women } \\
\text { who undergo abortion? }\end{array}$ & 97.8 & 97.9 & $85.7 *$ & 92.7 \\
\hline
\end{tabular}


Building Alliances from Ambivalence: Evaluation of Abortion Values Clarification Workshops with Stakeholders in . .

I was not fully aware of TOP and did not agree with backstreet abortion. After the workshop and seeing nurses trained to do this properly, I fully support this.

\section{Participant Behavioural Shifts}

Almost all participants $(96.3 \%)$ affirmed that the VC workshops had boosted self-awareness of their actions. Table 4 shows that a slight majority of attendees surveyed (52.4\%) reported that they had begun new activities as a consequence of the VC workshops. Such activities can generally be subdivided into two types: (1) diverse forms of advocacy; and (2) personal efforts to enhance reproductive health-care. New advocacy activities typically had three main target audiences, namely, communities, health-care providers and municipal authorities.

Over two-thirds $(70.2 \%)$ of participants attributed some form of personal behaviour change to their participation in the workshop. Those initially ambivalent towards TOP were slightly more likely to report changes in personal behaviour than those who were supportive of TOP services and those opposed to it initially $(\mathrm{p}<0.05)$. Examples of individuals' initiatives illustrate the scale and scope of behaviours prompted by the workshop. Many efforts centred upon disseminating information or providing support to facilities. Those projects took a number of forms, including initiating meetings, workshops, youth groups, video sessions and church sermons. Health providers reported making incremental improvements in the quality and quantity of services.

\section{I established an isolated new ward for the people who come for TOP, I gave more staff to the ward. A number of beds were added. (Female senior health manager from Vhembe District)}

Several health-care providers and community leaders reported beginning to provide individual client counselling. A female social worker from the Capricorn District said:

I am giving pre- and post-counselling about TOP in my office.

Table 4 Self-Reported Behavioural Shifts attributed to VC Workshop ( $\mathrm{n}=188$ )

\begin{tabular}{|c|c|c|c|c|}
\hline & $\begin{array}{c}\text { "Yes" among } \\
\text { those } \\
\text { previously } \\
\text { positive toward } \\
\text { TOP (\%) } \\
(\mathrm{n}=92)\end{array}$ & $\begin{array}{c}\text { "Yes" among } \\
\text { those } \\
\text { previously } \\
\text { undecided } \\
\text { about TOP }(\%) \\
(\mathrm{n}=49)\end{array}$ & $\begin{array}{l}\text { "Yes" among } \\
\text { those } \\
\text { previously } \\
\text { opposed to } \\
\text { TOP }(\%) \\
(\mathrm{n}=47)\end{array}$ & $\begin{array}{c}\text { Total } \\
(n=188)\end{array}$ \\
\hline $\begin{array}{l}\text { Has your personal behaviour changed } \\
\text { as a consequence of } \mathrm{VC} \text { workshops? }\end{array}$ & 62.6 & $78.7^{*}$ & 77.6 & 70.2 \\
\hline $\begin{array}{l}\text { Have you begun new activities as a } \\
\text { consequence of the VC workshop? }\end{array}$ & 50.5 & 59.2 & 50.1 & 52.4 \\
\hline $\begin{array}{l}\text { After the workshop, did you have } \\
\text { further contact with the organisers on } \\
\text { any issues related to the workshop? }\end{array}$ & 42.9 & 30.6 & 30.6 & 36.8 \\
\hline
\end{tabular}


96

African Journal of Reproductive Health

One senior health manager from Vhembe noted:

I saw CTOP as a single item (service only). I now see CTOP as a package including counselling, service and family planning.

A handful of participants reported petitioning the local government for changes. They advocated for TOP provision or information dissemination by directly addressing a government body or official. One female municipal councillor said she wrote a motivating report to the mayor asking for workshops.

Individual participant initiatives were more common than collective actions by groups of participants. While most participants (64.0\%) recalled discussing the potential value of working as a group on TOP barriers, only one in five $(21.9 \%)$ reported that they had held a subsequent or follow-up meeting to address the action plan developed in the workshops.

In addition to those aspects specifically measured in the study, there were other ancillary outcomes that merit mention. Foremost was the fact that the Limpopo DoH assumed a visible leadership role throughout the implementation and evaluation processes and increased its ownership of and leadership on the TOP issue in general. The Limpopo DoH involved new stakeholders in the issue, prompting one traditional healer from Vhembe to observe:

\section{I didn't believe that traditional healers and health sectors could work together. Now I know that it is possible.}

Additionally, interest was stimulated by the VC intervention as news about the workshops spread through the communities. The Limpopo $\mathrm{DoH}$ and Ipas received numerous formal requests for more $\mathrm{VC}$ workshops, and other provinces have expressed interest in replicating the intervention.

\section{Discussion}

The reported outcomes of the workshops need to be contextualised by close scrutiny of the inputs. It is noteworthy that $48.0-64.0 \%$ of respondents were supportive of TOP services prior to the intervention. This raises several interrelated strategic questions about VC interventions. In an era of scarce resources, is a stakeholder transition from support to advocacy as important as the initial shift from opposition to tolerance? Can those distinct shifts be achieved simultaneously via the same intervention? Which should be prioritised? Further research using purposive recruitment and observational methods is needed to determine how the mix of participants in $\mathrm{VC}$ workshops affects the outcomes, and whether stage-matching is even more effective than heterogeneous groupings.

\section{Limitations}

This study suffers from two major limitations and several design constraints. First, since preworkshop attitudes and behaviours were not measured, causality between workshop participation and advocacy behaviours cannot be confidently established. The subjectivity of participants' post-hoc recall is a significant limitation. Assessments conducted in the weeks and months following an intervention, such as the ones conducted in this project, are prone to recall and telescope bias (e.g., not remembering prior positions or the correct point in time when prior positions were held). Second, we were able to interview only 193 of 645 participants (30\%). This loss to follow-up was largely a function of missing or outdated contact data, we therefore have no reason to believe that non-response is systematic or related to abortion attitudes, but that possibility exists. Data collectors anecdotally reported that refusals were more likely among those opposed to the CTOP Act. By under-sampling participants with lingering opposition to TOP, it is likely that this study slightly overestimates the effectiveness of the intervention. How-

African Journal of Reproductive Health Vol. 9 No.3 December 2005 
ever, given the small proportion of overt refusals $(<5 \%)$, this systematic response bias is small.

Testing a cognitive-behavioural intervention on diverse rural audiences does not lend itself easily to evaluation by traditional methods due to the challenges in measuring the array of possible attitudinal and behavioural shifts of stakeholders. Finally, a verification of the actual content of participants' advocacy behaviour was not conducted; hence, their quality and impact are unknown.

\section{Recommendations}

Future VC workshops can be enhanced to maximise their impact through modifications in recruitment, curricular content matched to participant needs, and monitoring.

In the recruitment process, it is important to assess pre-workshop attitude and behaviour of potential participants. At a minimum, this would include conducting both pre- and post-workshop surveys of baseline knowledge, attitude and behaviour.

To maximise the impact of curricular content, we recommend matching the exercises to the attitudinal stage of participants as well as specific stakeholders' locus of control. For example, for those already supportive of TOP services, it would be wise to expand advocacy skills training. Exercises on workplace obstruction of services could be added for facility managers, whereas pastors and healers might value distinct content. If a desired outcome is collective action by stakeholders, workshops may need to include trust and team building in future iterations. To assure long-term impact, it is important to facilitate forums for the groups to meet again if they desire to continue working together.

The findings underscore the need to devote additional attention to the complex issue of second trimester abortion. While most abortionrelated maternal deaths in South Africa occur in the second trimester, attendees in this workshop remained unclear about the circumstances under which second trimester care is permitted. Greater attention needs to be paid to building support for safe second trimester services.

Future iterations should have a monitoring and evaluation component that would include both pre- and post-assessments, process measures and a matched control group to facilitate the measurement of changes attributable to participation.

\section{Conclusions}

This project sought to evaluate the effectiveness of VC workshops and to make recommendations for their further refinement. Although design limitations preclude the rigorous determination of causality, the consistent direction of positive findings lends credence to the notion that values clarification may be effective. While VC workshops do not resolve all of the problems with lack of access to abortion services, this preliminary study suggests that they may have an important role to play in creating a climate supportive of TOP access. However, future assessments of the number of facilities offering TOP are needed to determine if VC workshops have a tangible impact on access.

Although the workshops did not change all negative opinions, they did inform participants and favoured self-reported shift toward tolerance. Moreover, the workshops inspired a number of attendees to report advocacy on the issue of reproductive freedom and to assume personal responsibility for resolving local service provision problems.

The VC workshops were not intended as a quick fix for ingrained opposition to TOP, nor were they likely to stimulate a sea change in entrenched bureaucracies with structural problems. These VC workshops were provided as part of a long-term strategy and comprehensive package that also addresses equipment, training and policy obstacles.

Opening minds and hearts to the abortion issue is a complex process. The importance of 
98 African Journal of Reproductive Health

identifying the tools needed to achieve this change at the personal, community and facility levels has never been greater, however, and the role of values clarification in that process is increasingly clear. VC workshops are effective. As a tool of social change they are flexible enough to adapt to diverse cultural contexts and heterogeneous populations yet rigorous enough to be meaningful and promote tangible results.

\section{Acknowledgements}

The authors of this report would like to thank all the people who made this study possible. We would like to thank the Dickler Family Foundation for sponsoring this evaluation research and the European donors who supported the workshops themselves. We would also like to sincerely thank the Limpopo Department of Health and Welfare, the skilled workshop facilitators and data collectors. The suggestions of the anonymous reviewers are gratefully acknowledged.

\section{REFERENCES}

1. Harrison A, Montgomery ET, Lurie M and Wilkinson D. Barriers to implementing South Africa's Termination of Pregnancy Act in rural KwaZulu/Natal. Health Policy Plan 2000; 15(4): 424-431.

2. Mhlanga RE. Abortion: developments and impact in South Africa. Br Med Bull 2003; 67: 115-126.

3. Sibuyi MC. Provision of abortion services by midwives in Limpopo province of South Africa. Afr J Reprod Health 2004; 8(1): 75-78.

4. Braam T (Ed.). Barometer. Braamfontein: Reproductive Rights Alliance, 2002.

5. Gmeiner AC, Van Wyk S, Poggenpoel M and Myburgh CP. Support for nurses directly involved with women who chose to terminate a pregnancy. Curationis 2000; 23(1): 70-78.

6. Buga GA. Attitudes of medical students to induced abortion. East Afr Med J 2002; 79(5): 259-262.

7. Mitchell EMH, Mwaba K, Makoala MS and Trueman K. A facility assessment of termination of pregnancy (TOP) services in Limpopo Province, South Africa. Chapel Hill (NC): Ipas, 2004.

8. Dickson KE, Jewkes RK, Brown H, Levin J, Rees $\mathrm{H}$ and Mavuya L. Abortion service provision in South Africa three years after liberalization of the law. Stud Fam Plann 2003; 34(4): 277-284.

9. Sibuyi MC. Provision of abortion services by midwives in Limpopo province of South Africa. Afr J Reprod Health 2004; 8(1): 75-78.

10. Marais T. Provisional overall results from abortion values clarification workshop pilot study. Cape Town: Planned Parenthood Association of South Africa, 1996.

11. Onyango-Ouma W, Laisser R., Mbilima M, Araoye M, Pittman P, Agyepong I, Zakari M, Fonn S, Tanner M and Vlassoff C. An evaluation of Health Workers for Change in seven settings: a useful management and health system development tool. Health Policy Plan 16: 24-32.

12. Mitchell EMH, Trueman K, Gabriel M, Fine A and Manentsa N. Accelerating the pace of progress in South Africa: an evaluation of the impact of values clarification workshops on termination of pregnancy access in Limpopo Province. Johannesburg: Ipas, 2005.

13. Varkey SJ, Fonn S and Ketlhapile M. Health Workers for Choice. Johannesburg: Women's Health Project, 2001.

14. Fonn S and Xaba M. Health Workers for Change: A Manual to Improve Quality of Care. Women's Health Project, South Africa and UNDP/World Bank. WHO, Geneva, 1995.

15. Haaland $A$ and Vlassoff C. Introducing Health Workers for Change: from transformation theory to health systems in develop-

African Journal of Reproductive Health Vol. 9 No.3 December 2005 
Building Alliances from Ambivalence: Evaluation of Abortion Values Clarification Workshops with Stakeholders in ... 99

ing countries. Health Policy Plann 2001; 16(Suppl. 1): 1-6.

16. Varkey SJ, Fonn S and Ketlhapile M. Health

Workers for Choice. Johannesburg: Women's

Health Project, 2001.

17. Mitchell EMH, Trueman K, Gabriel M, Fine
A and Manentsa N. Accelerating the Pace of Progress in South Africa: an evaluation of the impact of values clarification workshops on termination of pregnancy access in Limpopo province. Johannesburg: Ipas, 2005. 